\title{
Resistência a antibióticos de Staphylococcus aureus isolados de dietas enterais em um hospital público de Minas Gerais
}

\section{Antibiotic resistance of Staphylococcus aureus isolated from enteral diets in a public hospital of Minas Gerais}

\author{
Joice de Fátima Laureano Martins ${ }^{1}$; Aurélia Dornelas de Oliveira Martins²; \\ Regina Célia Rodrigues Miranda Milagres ${ }^{3}$; Nélio José de Andrade ${ }^{4}$
}

\section{Resumo}

Dietas enterais constituem um excelente meio para crescimento microbiano, devido à sua composição rica em nutrientes e ao tempo de exposição à temperatura ambiente durante a administração. Dentre as bactérias patogênicas que podem ser encontradas nessas dietas, cita-se o Staphylococcus aureus, microrganismo oportunista encontrado na microbiota da membrana mucosa (bucal, nasal e oral) em seres humanos. Amostras de dieta enteral pós-administração e do ambiente utilizado para o seu preparo foram coletadas em um hospital público e analisadas quanto à presença de $S$. aureus. A contaminação foi evidenciada em $83 \%$ das amostras de dietas enterais, e, quanto ao ambiente, os valores encontrados se apresentam de acordo com a recomendação da APHA. As cepas isoladas foram submetidas a diferentes antibióticos, apresentando resistência à tetraciclina (100\%), eritromicina $(90,9 \%)$, cloranfenicol $(59,1 \%)$, estreptomicina $(22,72 \%)$, penicilina $(18,8 \%)$, vancomicina $(13,63 \%)$, ampicilina $(13,63 \%)$, amoxilina $(9,09 \%)$ e gentamicina $(4,54 \%)$. Devido à versatilidade no desenvolvimento de resistência a vários agentes antimicrobianos $S$. aureus sobrevive em ambientes hospitalares e pode ser difundido entre os pacientes. Palavras-chave: Dieta enteral. Staphylococcus aureus. Antibióticos.

\begin{abstract}
Enteral diets constitute an excellent means for microbial growth due to its composition rich in nutrients and its time of exposure to room temperature during application. Among the pathogenic bacteria there is the Staphylococcus aureus that is an opportunist microorganism found in the humans' mucous membrane (buccal, nasal and oral). Samples of enteral diet after application as well as of the environment used for the preparation of the diets, were collected in a public hospital in Minas Gerais and analyzed for the presence of S. aureus. The contamination by S. aureus was evidenced in $83 \%$ of the enteral diet samples. As for the environment, the values found were in conformity with APHA recommendation. The isolated strains were submitted to the evaluation of the resistance to different antibiotics. Resistance was observed for tetracycline (100\%), erythromycin (90,9\%), chloramphenicol (59,1\%), estreptomycin (22,72\%), penicillin $18,8 \%)$, vancomycin $(13,63 \%)$, ampicillin $(13,63 \%)$, amoxilin $(9,09 \%)$ and gentamicin $(4,54 \%)$. Due to the versatility in the resistance development to several antibiotics the $S$. aureus survives in hospital environments and can be diffused among patients.
\end{abstract}

Key words: Enteral diet. Staphylococcus aureus. Antibiotic.

\footnotetext{
1 Estudante de Nutrição da Universidade Federal de Viçosa (UFV), Campus Universitário, Departamento de Nutrição (DNS), cep.36570-000, Viçosa - MG. Endereço para correspondência: Rua Cândido Mendes nº 3, Centro, cep. 36515-000, GuidovalMG, Brasil, fone: (031) 8662-5710, E-mail: martinsjfl@yahoo.com.br

2 Estudante de Doutorado da UFV, Departamento de Tecnologia de Alimentos (DTA).

3 Técnica de nível superior do DNS, UFV.

4 Professor Titular do DTA, UFV.
} 


\section{Introdução}

Dietas enterais constituem um excelente meio para multiplicação microbiana. Sua composição, rica em nutrientes, e seu tempo de exposição à temperatura ambiente durante a administração podem propiciar o crescimento de microrganismos patogênicos e promover um aumento do risco de infecção hospitalar. A contaminação das dietas pode ocorrer de diversas formas, pelos próprios alimentos que não são estéreis, por exposição à contaminação durante o preparo e mistura dos ingredientes, e ainda, pelos manipuladores. Em seus estudos, Sullivan et al. (2001), confirmaram que a maioria dos pacientes (63\%) que recebem dietas por via enteral torna-se colonizada com os microrganismos isolados da própria dieta.

As doenças transmitidas por alimentos consomem recursos com cuidados de saúde e causam mortalidade e morbidade em todo o mundo. Entre os sintomas agudos mais comuns podem ser citados diarréias, vômito, problemas gastrintestinais, náuseas e, algumas vezes, febre (MENDONÇA, 2003).

Staphylococcus aureus é um microrganismo oportunista encontrado na microbiota membrana mucosa (bucal, nasal e oral) em seres humanos. Esse patógeno causa sérias infecções quando em contato com o organismo humano (BERNARDO et al., 2005). Cerca $50 \%$ das pessoas sadias são portadoras de $S$. aureus nas fossas nasais e garganta (SILVA; GANDRA, 2004).

O gênero Staphylococcus é formado por 32 espécies e $S$. aureus é a mais relacionada a surtos de intoxicação alimentar, devido à capacidade de produzir enterotoxina (SILVA; GANDRA, 2004). Cepas de $S$. aureus enterotoxigênicas podem ser encontradas nos alimentos a partir de sua obtenção primária, especialmente alimentos de origem animal. $\mathrm{O}$ alimento é contaminado também durante o processamento, a partir de manipuladores e a manipulação inadequada dos alimentos por portadores da bactéria ou por pessoas com ulcerações nos braços e nas mãos, constitui-se na principal fonte de contaminação dos alimentos por estafilococos (MENDONÇA, 2003). As doenças causadas por toxinas apresentam amplo espectro de manifestações clínicas, como celulite, síndrome da pele escaldada, síndrome do choque tóxico e intoxicação alimentar (SILVA; GANDRA, 2004).

Staphylococcus aureus é uma bactéria patogênica que, freqüentemente, acomete pacientes hospitalizados, associando-se a morbidades e mortes (SPIANDORELLO et al., 2000). O tratamento de patologias causadas por bactérias ocorre por meio do uso de antibióticos compostos químicos que, em pequenas concentrações, são capazes de ocasionar a morte ou a inibição do crescimento. Porém, quando utilizados excessivamente, principalmente os mais antigos, têm-se tornado, na maioria das vezes, ineficazes, devido à seleção de cepas resistentes (TIBBETTS; LIN; WU, 2003). Outro problema está no fato de que os antibióticos têm sido empregados inadequadamente na medicina humana até mesmo para o tratamento de infecções virais para as quais não apresentam nenhum efeito (PETRONE; BALDASSI; BIDOIA, 2004).

Infecções causadas por patógenos resistentes a antibióticos constituem um desafio para a medicina, uma vez que os microrganismos patogênicos podem ganhar resistência a todos os antibióticos antes eficazes, levando, assim, a um aumento incontrolado de epidemias causadas por doenças bacterianas que não poderão ser tratadas.

Em virtude da facilidade que $S$. aureus tem demonstrado para desenvolver resistência a antimicrobianos, é provável que se tenha dificuldade no tratamento de infecções estafilocócicas. Portanto, é importante realizar estudos com objetivo de verificar essa resistência, e conscientizar os responsáveis pela Unidade de Alimentação e Nutrição (UAN) para um controle da proliferação desse microrganismo tentando diminuir o risco de exposição da população. 


\section{Material e Métodos}

As amostras foram coletadas no setor de produção de dieta enteral em um hospital geral, com capacidade para mais de 100 leitos, situado na cidade de Viçosa, MG. Todas as amostras foram analisadas três vezes, colhidas em dias diferentes e em triplicata. Em cada visita eram coletadas três amostras compostas de diferentes dietas no final da administração ao paciente. Também foram coletadas amostras referentes ao manipulador da dieta e também bancada e liquidificador utilizado no seu preparo. As coletas ocorreram após higienização dos pontos a serem avaliados.

Após coletadas, as amostras de dieta enteral foram acondicionadas em caixas isotérmicas contendo gelo, e transportadas ao laboratório de Higiene de Alimentos do Departamento de Nutrição e Saúde da Universidade Federal de Viçosa (UFV), onde foi realizada a pesquisa de microrganismos do tipo Staphylococcus aureus. De cada amostra, foram pesados, assepticamente, 25 gramas da dieta e adicionados $225 \mathrm{~mL}$ de água peptonada $0,1 \%(\mathrm{p} / \mathrm{v}$ - Biobras), a fim de obter-se a diluição inicial $\left(10^{-1}\right)$. Após homogeneização, as amostras foram submetidas a diluições seriadas, plaqueadas em ágar Baird Parker (MERCK) acrescido de telurito de potássio e solução de gema de foram incubadas a $35^{\circ} \mathrm{C}$ por 48 horas, conforme metodologia da American Public Health Association (APHA), descrito por Sveum et al. (1992).

A verificação da presença de $S$. aureus na bancada, liquidificador e manipulador foi realizada antes do preparo da dieta, após higienização rotineira da sala de preparo com solução de hipoclorito de sódio 200 ppm e álcool $70{ }^{\circ} \mathrm{GL}$. A higienização do liquidificador foi realizada com hipoclorito de sódio 100 ppm e do manipulador com álcool $70^{\circ} \mathrm{GL}$.

As análises foram desenvolvidas por meio da técnica do $s w a b$, adotando procedimento proposto pela APHA, descrito por Sveum et al. (1992). Para a realização das análises, foi utilizado $s w a b$ de algodão com $2 \mathrm{~cm}$ de comprimento e $0,5 \mathrm{~cm}$ de diâmetro. Os swabs foram esterilizados em autoclave a $121^{\circ} \mathrm{C}$ por 15 minutos.

Para análise da bancada e liquidificador, o swab umedecido em água peptonada $1 \%$, foi friccionado, formando um ângulo de $30^{\circ}$ com a superfície, por três vezes numa área de $100 \mathrm{~cm}^{2}$. Em seguida, os microrganismos coletados foram transferidos para tubos de ensaio contendo $10 \mathrm{~mL}$ de solução água peptonada acrescida de $0,5 \%$ de tiossulfato de sódio, esterilizada a $121^{\circ} \mathrm{C}$ por 15 minutos, sendo os resultados expressos em UFC (Unidade Formadora de Colônia) $/ \mathrm{cm}^{2}$.

Para análise do manipulador, o swab umedecido foi friccionado numa área correspondente às superfícies das palmas e bordas das mãos, partindo da região dos punhos. De forma angular, o $s w a b$ foi passado com movimentos giratórios da parte inferior das palmas até a extremidade dos dedos e voltando ao punho, repetindo-se este procedimento três vezes na direção de cada dedo. Em seguida, o swab foi friccionado entre os dedos do manipulador. Os microrganismos aderidos ao swab foram transferidos para tubos de ensaio contendo $10 \mathrm{~mL}$ água peptonada, acrescida de $0,5 \%$ de tiossulfato de sódio, esterilizada a $121^{\circ} \mathrm{C}$ por 15 minutos. Os resultados foram expressos em UFC/mão.

Após coletadas as amostras da bancada, liquidificador e manipulador, as mesmas foram transportadas, sob refrigeração, para o laboratório de higiene industrial e microbiologia de alimentos da Universidade Federal de Viçosa (MG), para a análise de $S$. aureus.

A identificação de $S$. aureus foi realizada pelo método de coloração de Gram, atividade catalase e coagulase. Todos cocos Gram-positivos, catalase e coagulase positivos foram isolados novamente para a realização do teste de antibiograma, pelo método de Bauer e Kirby (1966).

Foram utilizados no teste discos de tetraciclina (30 mg), eritromicina (15 mg), cloranfenicol (30 mg), estreptomicina (10 $\mathrm{mg}$ ), penicilina (10 UI), vancomicina (30 mg), ampicilina (10 mg), amoxilina 
(20 mg) e gentamicina (10 mg). As zonas de inibição foram medidas e sua susceptibilidade foi expressa em termos de resistência de acordo com CLSI (CLINICAL AND LABORATORY STANDARDS INSTITUTE, 2003).

\section{Resultados e Discussão}

O setor de preparo de dieta enteral constitui-se, nesse hospital, um setor isolado da Unidade de Alimentação da Nutrição (UAN), e isso é um fator positivo, pois o ambiente hospitalar guarda uma íntima relação com as infecções hospitalares, podendo proporcionar focos de contato e de transmissão de patógenos (ANDRADE; ANGERAMI; PADOVANI, 2000). Outro foco de contaminação importante é o próprio paciente. Segundo Castro e Iaria (1984), uma das principais fontes de contaminação de $S$. aureus em UAN são as fossas nasais dos manipuladores. Em seus estudos, esses autores analisaram 78 manipuladores de alimentos em cozinhas hospitalares e observaram que $42,3 \%$ destes continham a bactéria nas fossas nasais.

A Tabela 1 mostra a contagem de $S$. aureus na bancada da sala de preparo da dieta enteral, no manipulador responsável pelo preparo da dieta e no liquidificador utilizado para a homogeneização da mesma.

Tabela 1. Contagem de Staphylococus aureus em diferentes pontos da sala de preparo de dieta enteral dados em Unidades Formadoras de Colônia (UFC)

\begin{tabular}{cc}
\hline Fontes de contaminação & Contagem de S. aureus \\
\hline Bancada & $<0,4 \mathrm{UFC} / \mathrm{cm}^{2}$ \\
Manipulador & $<1,0 \mathrm{UFC} / \mathrm{mão}^{2}$ \\
Liquidificador & $<0,4 \mathrm{UFC} / \mathrm{cm}^{2}$ \\
\hline
\end{tabular}

Não existem padrões de legislação referentes à qualidade microbiológica de equipamentos e utensílios que entram em contato com os alimentos durante $o$ processamento. No entanto, a APHA recomenda 2 UFC/ $\mathrm{cm}^{2}$ para mesófilos aeróbios (SVEUM et al., 1992), portanto, a contagem de $S$. aureus na bancada e no liquidificador pode ser considerada baixa, não implicando em risco para os pacientes. Estes dados sugerem que o procedimento de higienização adotado para a bancada e liquidificador mostram-se eficientes contra esse grupo de microrganismo.

Em relação ao manipulador, é inexistente uma especificação ou padrão de S. aureus para uma contagem microbiana. Andrade e Macêdo (1996), porém relatam que a Organização Mundial da Saúde (OMS) recomenda para condições higiênicas satisfatórias de manipuladores de alimentos uma contagem de $S$. aureus inferior a $1,5 \times 10^{2} \mathrm{UFC} /$ mão. De acordo com os dados, o manipulador avaliado apresentou uma contagem de $S$. aureus inferior ao recomendado, indicando a eficiência do processo de higienização estabelecido pelo mesmo.

Das amostras de dietas enterais coletadas após a administração, $83 \%$ apresentaram contaminação com S. aureus. Essa contaminação pode ser atribuída tanto ao tempo em que a dieta enteral fica exposta à temperatura ambiente durante a administração, quanto á água utilizada no preparo da mesma, uma vez que o manipulador, a bancada e o liquidificador adotados para o preparo das dietas estavam de acordo com as recomendações da OMS e APHA.

Segundo Santos et al. (2005), a alta freqüência de contaminação observada nas fórmulas enterais, pode estar relacionada com seus constituintes. Estes ingredientes apresentam-se como substratos favoráveis ao crescimento microbiano. Ademais, modificações ou manipulações inadequadas, antes da 
sua administração ao paciente, também são fatores potencias de contaminação.

As 50 cepas de $S$. aureus isoladas das dietas enterais foram avaliadas quanto à resistência frente a diferentes antibióticos (Figura 1).

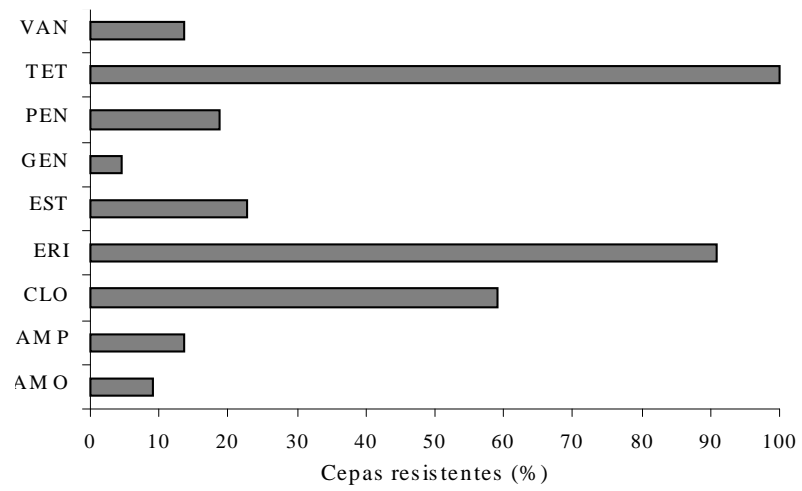

Figura 1. Resistência de Staphylococcus aureus isolados de dietas enterais frente a diversos antibióticos. Legenda: VAN: vancomicina, TET: tetraciclina, PEN: penicilina, GEN: gentamicina, EST: estreptomicina, ERI: eritromicina, CLO: cloranfenicol, AMP: ampicilina, AMO: amoxilina.

A resistência verificada a esses antibióticos em especial à tetraciclina que apresentou uma resistência de $100 \%$, evidencia a facilidade que esses microrganismos têm de desenvolver resistência a antimicrobianos. A resistência à penicilina, ampicilina e amoxilina foram respectivamente 18,8\%, 13,63\% e 9,09\%. Segundo Petrone, Baldassi e Bidoia (2004), cerca de $95 \%$ das cepas de S. aureus de todo o mundo, são resistentes para penicilina e ampicilina, e, em alguns dos hospitais, mais de $60 \%$ das linhagens são resistentes a meticilina, grupo dos â-lactâmicos. Spiandorello et al. (2000) relatam que uma das primeiras drogas desenvolvidas para vencer esse microrganismo foram as sulfonamidas, sem muito sucesso. A partir de 1942, a penicilina passou a ser utilizada para o tratamento de seres humanos e rapidamente reduziu a mortalidade de 80 para $35 \%$ (JOHN; BARG, 1996).

Quanto ao macrolídeo eritromicina, a maioria das cepas avaliadas $(90,9 \%)$ apresentou resistência a essa droga. Esse resultado, de acordo com Hardy, Hensey e Beyer (1988), que tem mostrado cepas de $S$. aureus resistentes a essa classe de antibióticos. Farias et al. (1997), ao estudar o padrão de sensibilidade de 117 amostras clínicas de $S$. aureus sensíveis a oxacilina isoladas em 12 hospitais de diferentes localidades, verificaram que a maioria das amostras avaliadas foi sensível a gentamicina. Resultado compatível com o encontrado neste estudo, em que apenas $4,54 \%$ das cepas avaliadas apresentaram resistência a esse antibiótico.

Para os antibióticos cloranfenicol, estreptomicina e vancomicina, a porcentagem de cepas resistentes foi de 59,1;22,72 e 13,63\%, respectivamente. Entre os antibióticos, a resistência à vancomicina é a mais preocupante, por ser um antibiótico de última geração e amplamente eficaz contra infecções clínicas causadas por patógenos multi-resistentes (NICAS et al., 1989). Em seus estudos, Farias et al. (1997), verificaram que nenhuma das cepas de $S$. aureus avaliadas foi resistente à vancomicina e aos demais glicopeptídeos testados. A baixa resistência de S. aureus a vancomicina foi evidenciada por Tynkkynen, Singh e Varmanen (1998), em um estudo onde este antibiótico foi utilizado em diversas infecções causadas por bactérias Gram-positivas, particularmente o Staphylococcus spp.

Os resultados desse estudo revelam um quadro preocupante, visto que muitos pacientes são submetidos indiscriminadamente a esses antibióticos. Esse fator pode proporcionar a seleção de cepas resistentes, particularmente o $S$. aureus.

\section{Conclusão}

Devido à versatilidade no desenvolvimento de resistência a vários agentes antimicrobianos o $S$. aureus sobrevive em ambientes hospitalares e pode ser difundido entre os pacientes, de modo que pode haver dificuldade no tratamento de infecções estafilocócicas. É imprescindível um maior controle higiênico-sanitário de dietas enterais em pacientes hospitalizados, que apresentam maior susceptibilidade a microrganismos oportunistas. 
A partir dos dados obtidos nesse estudo, verificase a importância de uma iniciativa de os profissionais de saúde aplicarem medidas de controle da proliferação desse microrganismo, por meio da implantação de um rigoroso sistema de controle de qualidade microbiológica não só nas áreas de manipulação das dietas enterais, mas também durante todo o processo de administração da mesma, com isso, busca-se diminuir o risco de exposição da população a esses microbianos.

\section{Referências}

ANDRADE, D.; ANGERAMI, E. L. S.; PANDOVANI, C. R. Condição microbiológica dos leitos hospitalares antes e depois da limpeza. Revista de Saúde Pública, Ribeirão Preto, v.34, n.2, p.163-169, 2000.

ANDRADE, N. J.; MACÊDO, J. A. B. Higienização da indústria de alimentos. São Paulo: Varela, 1996.

BAUER, A. W.; KIRBY, W. M. M.; SHERRIS, J.C.; TURCK, M. Antibiotic susceptibility testing by a standardized single disk method. American Journal of Clinical Pathology, Philadelphia, v.45, p.493-496, 1966.

BERNARDO, W.L.C.; BORIOLLO, M. F. G.; GONÇALVES, R. B.; HÖFLING, J. F. Staphylococcus aureus ampicillinresistant from the odontological clinic environment. Revista do Instituto de Medicina Tropical de São Paulo, São Paulo, v.1, p.19-24, 2005.

CASTRO, M. M. M. V.; IARIA, S. T. Staphylococcus aureus enterotoxigênico no vestíbulo nasal de manipuladores de alimentos em cozinhas hospitalares do Município de João Pessoa. Revista de Saúde Pública, Ribeirão Preto, v.18, n.3, p.235-245, 1984.

FARIAS, W. V.L.; SADER, H. S.; LEME, I. L.; PIGNATARI, A. C. Padrão de sensibilidade de 117 amostras clínicas de Staphylococcus aureus isoladas em 12 hospitais. Revista da Associação Médica Brasileira, São Paulo, v.43, n.3, p.199-204, 1997.

HARDY, D.; HENSEY, D.; BEYER, J. Comparative in vitro activities of new 14-, 15- and 16-membered macrolides. Antimicrobial Agents and Chemotherapy, Bethesda, v.1, n.32, p.710-719, 1988.

JOHN, J. F.; BARG, N. Staphylococcus aureus. In: MAYHALL, C. G. Hospital epidemiology and infection control. Baltimore: Williams \& Wilkins; 1996. p.271-290.

MENDONÇA, R. C. S. Patógenos na indústria de carnes e derivados. In: MENDONÇA, R. C. S.; BRABES, K. C. S.;
OLIVEIRA, K. A. M.,; VIEIRA, É. N. R. Qualidade e segurança na produção e consumo. Viçosa: Gráfica Universitária, 2003. p.21-48.

CLINICAL AND LABORATORY STANDARDS INSTITUTE. Performance Standard for Antimicrobial Disk Susceptibility Testing: Tables M100-S13. Wayne, PA: NCCLS, 2003.

NICAS, T. I. COLE, C. T.; PRESTON, D. A.; SCHABEL, A. A.; NAGARAJAN, R. Activity of glycopeptides against vancomycin-resistant Gram-positive bacteria. Antimicrobial Agents and Chemotherapy, Bethesda, v.33, p.1477-1481, 1989.

PETRONE, R. R. C. B.; BALDASSI, L.; BIDOIA, E., Sensibilidade de Staphylococcus aureus aos extratos da Aristolochia gigantea mart. e zucc. Arquivos do Instituto Biológico, São Paulo, v.71, supl., p.576-578, 2004.

SANTOS, B. H. C.; COSTA, A. C.; SOUZA, E. L.; SOUSA, C. P. Klebsiella pneumoniae como agente contaminante de dietas enterais artesanais. Revista de Higiene Alimentar, São Paulo, v.19, n.131, p.58-60, 2005.

SILVA, W. P.; GANDRA, E. A. Estafilococos coagulase positiva: patógenos de importância em alimentos. Revista de Higiene Alimentar, São Paulo, v.18, n.122, p.32-40, 2004.

SPIANDORELLO, W. P.; MORSH, F.; SEBBEN, S.; SPIANDORELLO, F. S. A. A resistência do Staphylococcus aureus à oxacilina em hospital de Caxias do Sul. Revista AMRIGS, Porto Alegre, v.44, n.3-4, p.120$125,2000$.

SULLIVAN, M. M.; SORREDA-ESGUERRA, P.; SANTOS, E. E.; PLATONX, B. G.; CASTRO, C. G.; IDRISALMAN, E. R. Bacterial contamination of blenderized whole food and commercial enteral tube feedings in the Philippines. Journal of Hospital Infection, London, v.49, n.4, p.268273, 2001.

SVEUM, W. H.; MOBERG, L. J.; RUDE, R. A.; FRANK, J. F. Microbiological monitoring of the food processing environment. In: VANDERZANT, C.; SPLITTSTOESSER, F. Compendium of methods for the microbiological examination of foods. 3rd ed. Washington: American Public Health Association, 1992. p.51-74.

TIBBETTS, R. J.; LIN, T. L.; WU, C. C., Phenotypic evidence for inducible multiple antimicrobial resistance in Salmonella choleraesuis. FEMS Microbiology Letters, Amsterdam, v.218, p.333-338, 2003.

TYNKKYNEN, S.; SINGH, K., V.; VARMANEN, P. Vancomycin resistanse factor of Lactobacillus rhamnosus GG in relation to enterococcal vancomycin resistanse (van) genes. International Journal of Food Microbiology, Amsterdam, v.41, p.195-204, 1998. 